\title{
Morphometric Analysis Program (MAP): Descripción y aplicación en la detección de displasias corticales focales en pacientes con epilepsia refractaria
}

Gonzalo Araya R. ${ }^{*}$, Ximena Stecher G. ${ }^{2}$, Valeria Schonstedt G. ${ }^{3}$, Claudio Silva F. $^{4}$, Rodrigo Araya ${ }^{5}{ }^{5}$, César Salinas G. ${ }^{6}$

1. Msc. Ingeniería Biomédica. TM Radiología y Física Medica. Clínica Alemana de Santiago. Santiago, Chile.

2. Neurorradióloga pediátrica. Clínica Alemana de Santiago. Facultad de Medicina. Universidad del Desarrollo. Santiago, Chile.

3. Neurorradióloga pediátrica. Clínica Alemana de Santiago. Facultad de Medicina. Universidad del Desarrollo. Santiago, Chile.

4. Médico Radiólogo. Clínica Alemana de Santiago, Facultad de Medicina. Universidad del Desarrollo. Santiago, Chile.

5. Fellow de Neurorradiología. Facultad de Medicina Clínica Alemana. Universidad del Desarrollo. Santiago, Chile.

6. TM Radiología y Física médica. Clínica Alemana de Santiago. Universidad del Desarrollo. Santiago, Chile.

Morphometric Analysis Program (MAP): Description and application in the detection of focal cortical dysplasias in patients with refractory epilepsy.

\section{Resumen:}

Las displasias corticales focales son una causa común de Epilepsia Refractaria. Los hallazgos en la resonancia magnética pueden ser sutiles por lo que requiere de un examen de óptima calidad así como de gran expertise y dedicación del neuroradiólogo. Aún en las mejores condiciones, existe un considerable número de casos en que no se logra identificar una lesión. La sensibilidad de su detección varía entre el 20 a 70\%. Morphometic Analysis Program (MAP), es un programa de postprocesamiento de la imagen por resonancia magnética cuyo objetivo es aumentar la sensibilidad en la detección de displasis corticales focales (DFC). Este programa funciona comparando la forma, grosor y distribución de sustancia gris y sustancia blanca de un paciente con una base de datos de cerebros normales. MAP entrega, como resultado, 3 imágenes que corresponden a mapas estadísticos volumétricos denominados mapa junction, extension y thickness. Este artículo da a conocer el funcionamiento de MAP en sus distintas etapas así como su aplicación práctica, a través de algunos casos.

Palabras clave: Epilepsia refractaria; Displasia cortical focal; Imagen junction; Kernel; Morphometric analysis program (MAP); Modulación; Normalización; Segmentación.

\begin{abstract}
:
Focal cortical dysplasias are a common cause of refractory epilepsy. The findings on magnetic resonance imaging can be subtle, requiring optimal quality examination as well as extensive experience and dedication from the neuroradiologist. Even under the best conditions, there are a considerable number of cases in which an injury cannot be identified. The sensitivity of its detection varies between 20 and $70 \%$. The Morphometric Analysis Program (MAP), is a post-processing program of the magnetic resonance image whose objective is to increase the sensitivity in the detection of focal cortical dysplasia (CFD). This program works by comparing the shape, thickness and distribution of gray matter and white matter of a patient with a database of normal brains. As a result, MAP delivers 3 images that correspond to statistical volumetric maps called the union, extension and thickness map. This article discloses the operation of MAP in its different stages as well as its practical application, through some cases.
\end{abstract}

Keywords: Focal cortical dysplasia; Image junction; Kernel; Modulation; Morphometric analysis program (MAP); Normalization; Refractory epilepsy; Segmentation.

Araya G, et al. Morphometric Analysis Program (MAP): Descripción y aplicación en la detección de displasias corticales focales en pacientes con epilepsia refractaria. Rev Chil Radiol 2021; 27(2): 58-65.

${ }^{\star}$ Correspondencia: Gonzalo Araya R. I ga.araya.rojas@gmail.com

Trabajo enviado el 20 de mayo de 2020. Aceptado para publicación el 22 de septiembre de 2020. 


\section{Introducción}

Las displasias corticales focales corresponden a un grupo de malformaciones del desarrollo cortical, secundarias a una lesión durante los períodos de proliferación u organización cortical. Aunque su etiología no se encuentra completamente dilucidada, estas lesiones se caracterizan por la presencia de neuronas y células gliales anormales en una región de la corteza cerebral'.

Se estima que el $76 \%$ de los pacientes con epilepsia refractaria, es decir aquellas que no logran ser controladas con tratamiento farmacológico, poseen displasias corticales focales ${ }^{2}$. En estos pacientes, la resección quirúrgica del área epileptógena es el tratamiento de elección. El pronóstico postquirúrgico está determinado por la correcta identificación de la DCF en los estudios de imágenes. Sin embargo, la pesquisa de las DCF es un desafío radiológico, ya que los hallazgos pueden ser sutiles. La sensibilidad de la RM varía entre un $20 \%$ a $70 \%$ dependiendo de las características técnicas del examen y la expertise del neuroradiólogo ${ }^{3}$. Según Tassi et al. (2002) ${ }^{4}$, el 35\% de los pacientes con DCF confirmadas histológicamente, tenían resonancias magnéticas normales.

Para facilitar la detección de DCF se han desarrollado distintos sistemas de post-procesamiento de las imágenes, entre ellos se encuentra MAP. Este software fue creado y es distribuido por el doctor Huppertz (Swiss Epilepsy Centre, Zürich, Switzerland) ${ }^{5}$, y ha sido recientemente incorporado por importantes centros de epilepsia. Estudios han descrito un incremento de hasta un $12 \%$ en la detección de DCF al utilizar MAP respecto de la RM convencional ${ }^{6}$.

MAP detecta áreas sospechosas de DCF basado en sus características imagenológicas propias de estas lesiones. Estas son, la pérdida de definición córtico-subcortical, engrosamiento cortical y extensión anormal de los giros de la corteza (Figura 1). Compara así las imágenes del paciente respecto de un template de normalidad creada a partir de controles sanos adultos. Aquellas áreas que se alejan significativamente de la normalidad en cualquiera de los 3 criterios anteriormente descritos son sospechosas de corresponder a DCF.

Para poder sacar el máximo rendimiento a este programa es de suma importancia entender su funcionamiento, cual es la metodología que ocupa y sus resultados.

El objetivo de este artículo es dar a conocer cómo funciona MAP y su aplicación práctica con algunos ejemplos resprentativos desarrollados en nuestra institución.

\section{MAP (Morphometric Analysis Program)}

El objetivo de MAP es incrementar la sensibilidad en la detección de Displasias focales corticales, mediante el uso de un algoritmo de postproceso que está dentro de los scripts del software SPM, el cual, a su vez, trabaja en base al software de programación Matlab (Figura 2).

MAP utiliza imágenes obtenidas mediante una adquisición sagital ponderada en T1 con pulso de secuencia mprage (eco gradiente incoherente) de alta resolución definido como imagen de entrada para el postproceso. La salida o resultado del postproceso computacional MAP corresponde a tres mapas estadísticos volumétricos denominados: junction, extension $y$ thickness (Figura 3).

Estos tres mapas resaltan estas características en cada sujeto previamente comparándolos con un cerebro promedio normal (template). Estos mapas luego son utilizados para el análisis cualitativo realizado por neuroradiólogos expertos, quienes se basan en las imágenes volumétricas T1 de cada sujeto.

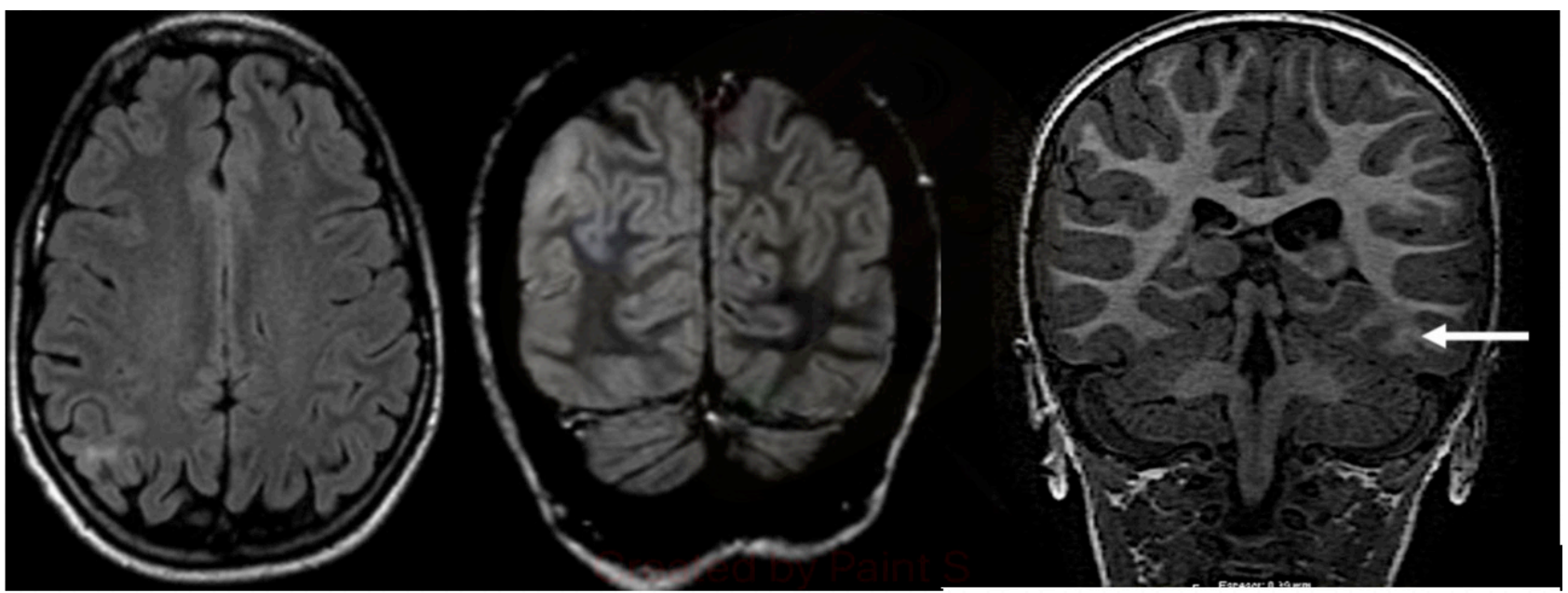

Figura 1: DISPLASIAS: imagen de la izquierda corresponden a engrosamiento cortical. Imagen de la derecha, corresponde a pérdida de definición de unión de SB-SG. 
- El mapa "junction" detecta las áreas de borramiento entre la unión de sustancia gris y sustancia blanca.

- El mapa "extensión" detecta algún giro anormal de la corteza cerebral.

- El mapa "thickness" detecta las zonas anormales de espesor de la corteza cerebral.

De estos tres mapas, el que ha presentado más utilidad en la experiencia práctica, es "junction" por lo que en este articulo nos centraremos en los pasos para poder obtener este mapa en particular.

\section{Conversión de formato de imágenes}

DICOM a NIFTI (Neuroimaging Informatics Technology Initiative) SPM trabaja con las imágenes en formato NIFTI, es por esto que necesitamos transformar las imágenes desde el formato DICOM a NIFTI, exigido por SPM.

El formato NIFTI viene de las siglas en ingles de "Neuroimaging Informatics Techonology Initiative". A diferencia del formato DICOM, NIFTI proporciona información de la orientación de la imagen y las
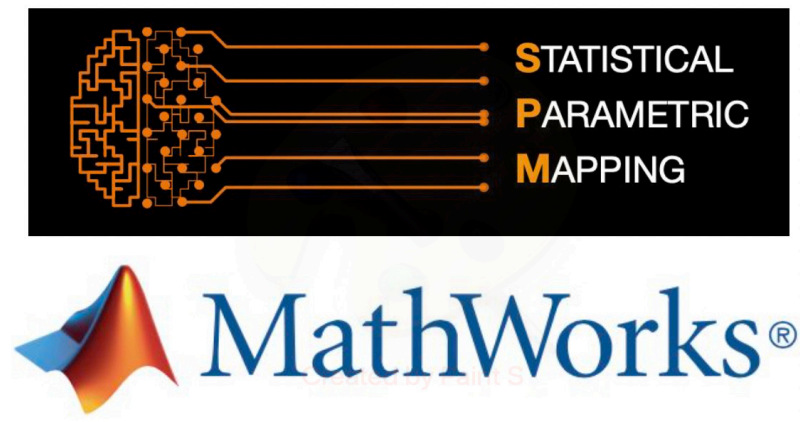

imágenes pueden estar hasta en 7 dimensiones.

Hay varias herramientas gratuitas de conversión de datos disponibles en la web que permiten transformar los datos de resonancia magnética del formato nativo del equipo a NIFTI. Entre las herramientas más empleadas se encuentran dcm2nii y MRIConvert. Los programas de análisis de neuroimagen, como FSL, SPM, FreeSurfer, etc., también tienen soluciones integradas para convertir los datos DICOM al formato específico empleado en esos paquetes, (que generalmente es NIFTI).

El postproceso se compone de varios pasos que a continuación se procede a detallar:

\section{Segmentación}

El proceso de segmentación consiste en clasificar cada vóxel como perteneciente a 3 grupos de tejidos cerebrales: sustancia gris, sustancia blanca o líquido cefalorraquideo (LCR).

Esto se logra a partir de la imagen volumétrica ponderada en T1, utilizando las distintas intensidades de señal de cada vóxel para determinar si es que pertenece a la sustancia blanca, sustancia gris o LCR. Esto permite que al construir el histograma de la imagen podemos segmentar por intensidad de señal cada grupo de vóxel en estos 3 grupos finales (SG, SB, LCR) (Figura 4).

Estos algoritmos de segmentación no clasifican los vóxeles de manera exclusiva en un grupo, si no que entregan una probabilidad de pertenecer a cada uno de estos 3 grupos, por lo que cada vóxel contiene un valor probabilístico.

Figura 2: Programas involucrados.

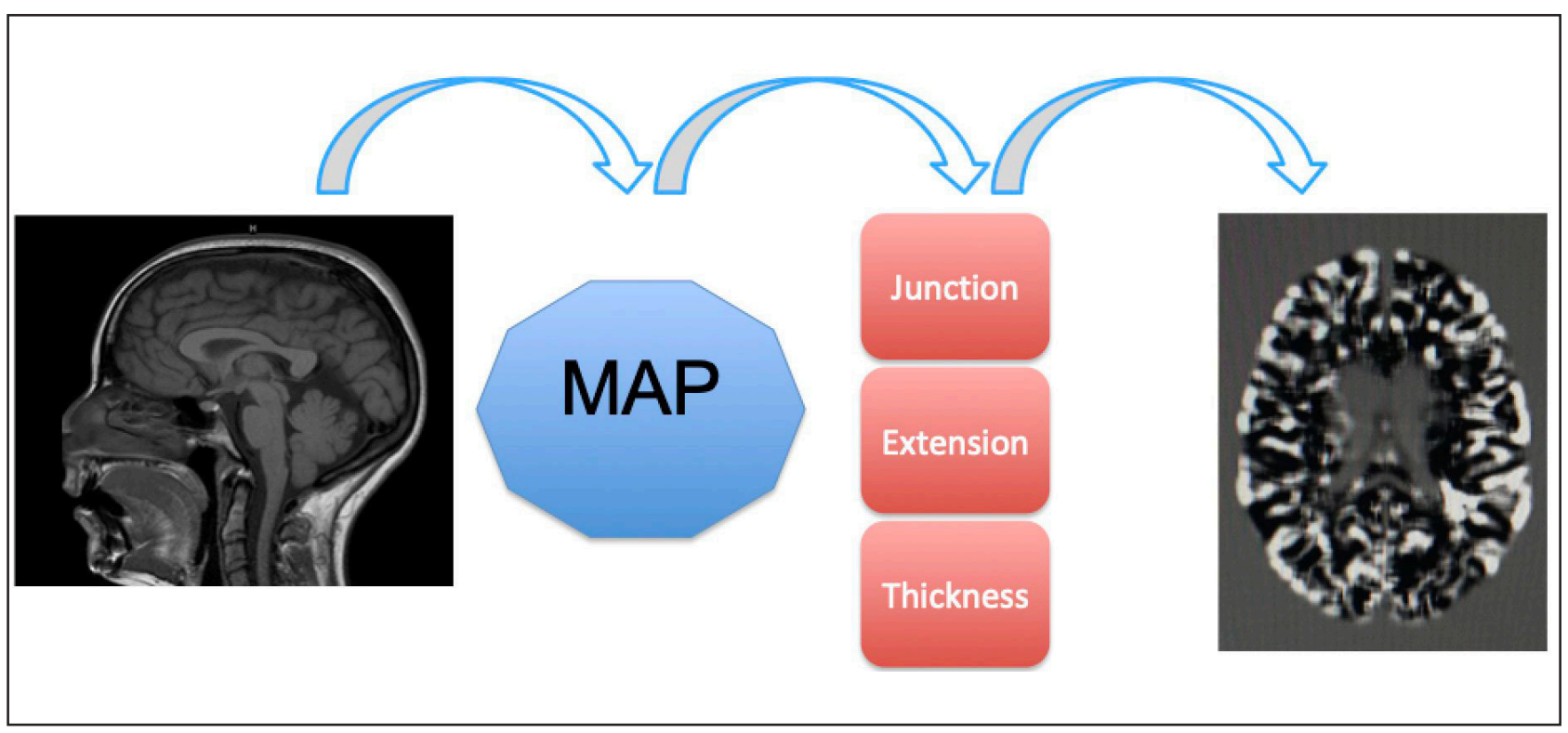

Figura 3: Entrada y salidas de MAP. 


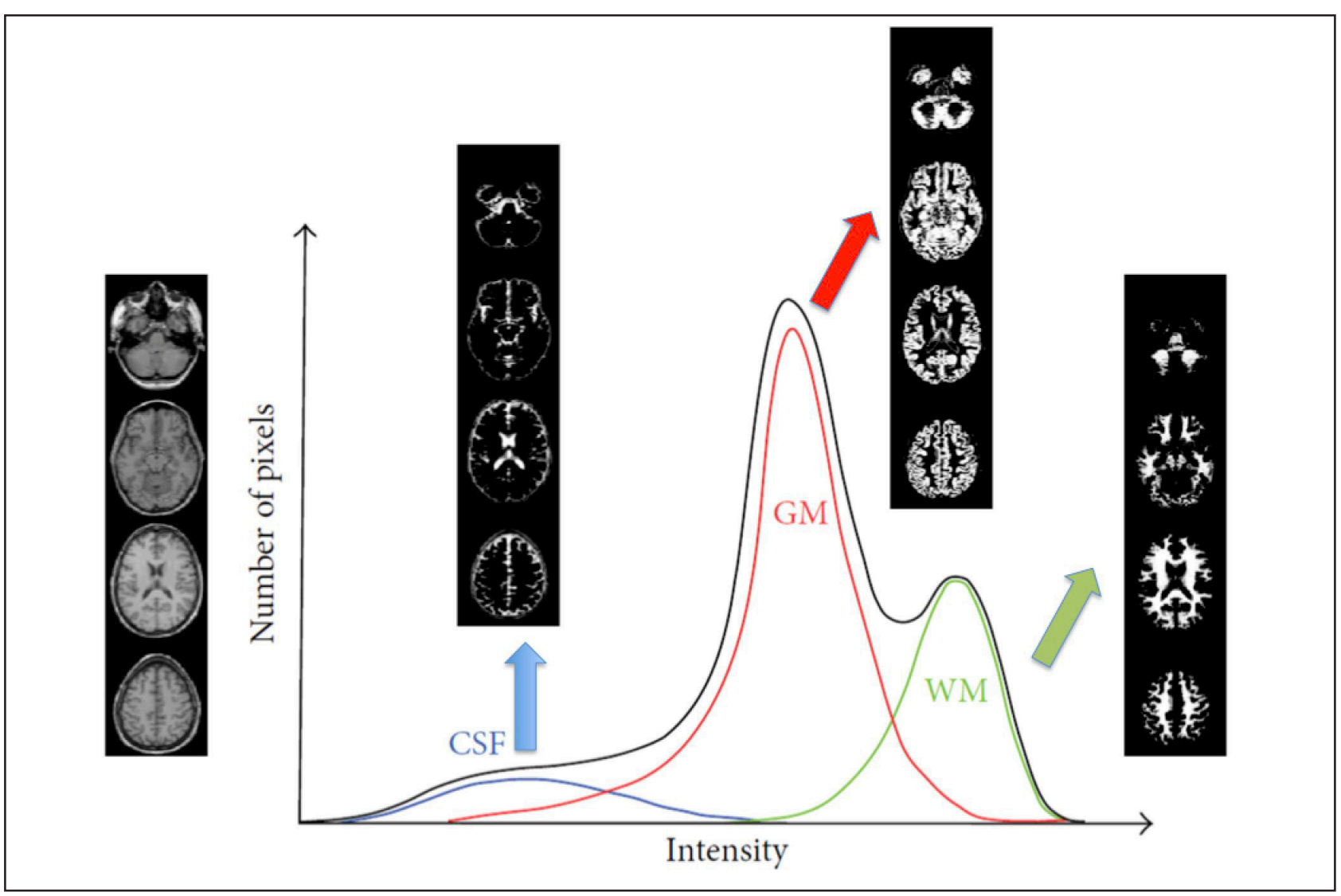

Figura 4: Histograma y segmentación.

\section{Normalización Espacial}

Dado que cada cerebro difiere en múltiples características, se requiere realizar un proceso de normalización para ser analizado.

Estos algoritmos de normalización deforman, en forma y tamaño, los cerebros que van a participar en el estudio y lo llevan a un espacio común, un cerebro estándar, pero sin perder los valores de probabilidad de cada vóxel obtenidos en el paso previo. Los espacios comunes más utilizados son el atlas de Talairach, el atlas del Instituto neurológico de Montreal (MNI), aunque también puede ser un template construido localmente con voluntarios en cada centro.

\section{Modulación}

Como resultado de la normalización espacial se pierde el valor de las diferencias volumétricas regionales del cerebro en estudio, por ello se recupera esta información dividiendo cada vóxel por un valor que representa la deformación que sufrió el vóxel en el proceso de normalización. Los vóxel que se contraen durante el proceso de normalización verán aumentado su valor después de la modulación, mientras que los vóxel que se expanden durante la normalización verán reducido su valor una vez que ocurra la modulación. El resultado final es que cada vóxel ya contiene la información de volumen que se había perdido en el proceso de normalización.

\section{Suavizado}

El proceso de suavizado tiene como objetivo el poder aumentar la relación señal-ruido de cada vóxel luego de los procesos previos. Esto se consigue promediando el valor de cada vóxel con los de sus vóxeles más cercanos, de esta forma se eliminan los valores no coherentes o bien que aparecen en un solo vóxel, lo cual lo mas probable corresponda a un artefacto.

En su mayoría el kernel de suavizado corresponde a uno de tipo gaussiano o normal con una amplitud a mitad de altura (FWHM) entre 4 y 16 mm (Figura 5). Este proceso de suavizado también ayuda a que los valores se distribuyan normalmente, de esta forma permite aplicar análisis paramétricos con resultados robustos (Figura 6).

\section{Construcción de Imagen Binaria}

Los promedios y las desviaciones estándar de las intensidades de señal de los vóxeles de la sustancia blanca (SB) y sustancia gris (SG) son utilizados para determinar umbrales mínimos y máximos para la construcción de una imagen binaria. 
Source layer

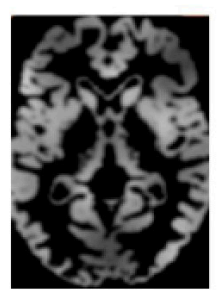

\begin{tabular}{|l|l|l|l|l|l|l|l|}
\hline 5 & 2 & 6 & 8 & 2 & 0 & 1 & 2 \\
\hline 4 & 3 & 4 & 5 & 1 & 9 & 6 & 3 \\
\hline 3 & 9 & 2 & 4 & 7 & 7 & 6 & 9 \\
\hline 1 & 3 & 4 & 6 & 8 & 2 & 2 & 1 \\
\hline 8 & 4 & 6 & 2 & 3 & 1 & 8 & 8 \\
\hline 5 & 8 & 9 & 0 & 1 & 0 & 2 & 3 \\
\hline 9 & 2 & 6 & 6 & 3 & 6 & 2 & 1 \\
\hline 9 & 8 & 8 & 2 & 6 & 3 & 4 & 5 \\
\hline
\end{tabular}

$(-1 \times 5)+(0 \times 2)+(1 \times 6)+$

$(2 \times 4)+(1 \times 3)+(2 \times 4)+$

$(1 \times 3)+(-2 \times 9)+(0 \times 2)=5$

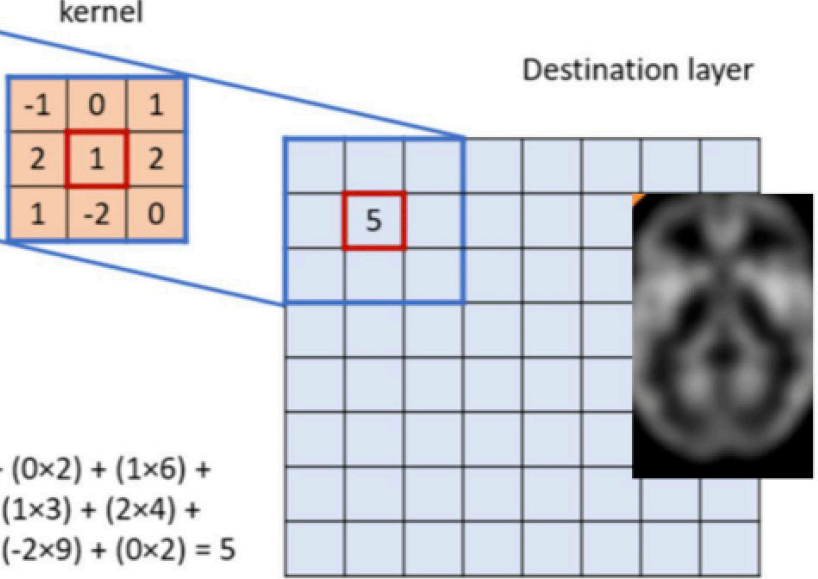

Figura 5: Filtro Kernel.

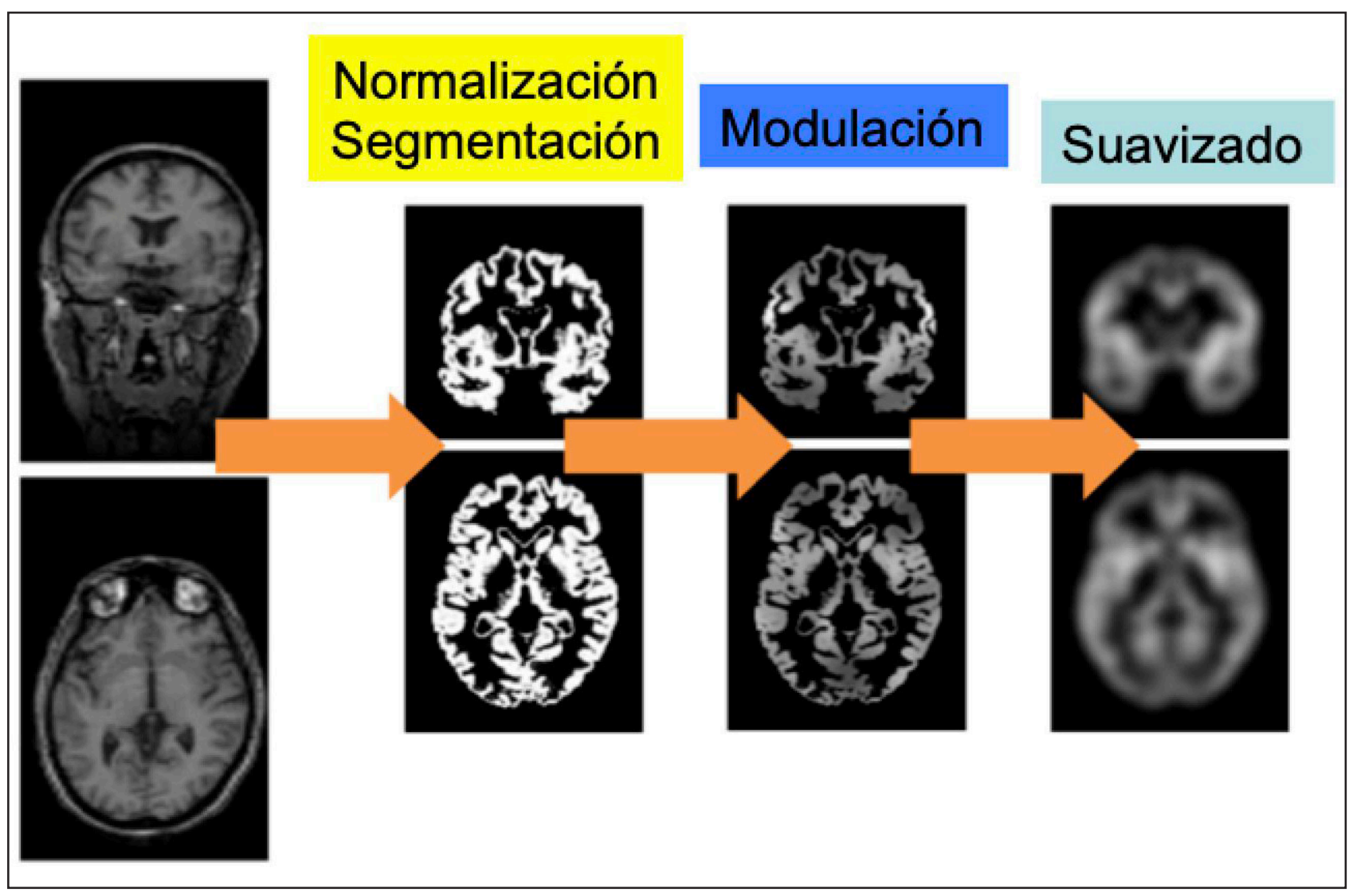

Figura 6: Pre-proceso completo. 
Los umbrales están definidos a través de las siguientes funciones:

Umbral mínimo = promedio SG+1/2 desviación estándar SG

Umbral máximo $=$ promedio $\mathrm{SB}+1 / 2$ desviación estándar SB

Cada vóxel con un valor de gris entre los umbrales definidos se le asigna un valor 1 , mientras que los otros vóxel se les asigna un valor 0 . La definición de estos umbrales hace que los vóxeles que contienen un valor de gris que no pertenece ni a la sustancia blanca ni a la gris logremos diferenciarlos asignándoles un valor 1. Los vóxeles con valores 1 tienen representación en la imagen resultante, mientras que los vóxeles con valores 0 no tienen representación en la imagen final. Las áreas del cerebro que también presentan un nivel de gris intermedio que pudieran dar falsos positivos en el proceso se eliminan con una máscara predefinida. Esto permite que se destaquen aquellos vóxeles que no cumplen con rango SG o SB, es decir, de sospecha de Displasias Corticales.

\section{Suavizado II}

La imagen binaria es filtrada a través de un filtro kernel de 53. Como resultado los vóxeles de valor 1 resaltan hiperintensos, valores altos de gris.

\section{Comparación con una base de datos normal, imagen junction}

La imagen binaria suavizada es comparada con una imagen construida con una base de datos de pacientes controles, esta última también es sometida a todos los pasos anteriores hasta llegar a esta imagen binaria suavizada la cual es comparada con la imagen binaria suavizada del paciente que estamos procesando. Estas dos imágenes se sustraen vóxel a vóxel obteniendo una imagen final que contiene los vóxel sospechosos de displasias corticales del paciente en cuestión. Esta última imagen resultante se denomina "imagen junction".

\section{Imagen z-score}

Aparte de calcular una imagen promedio con la base de datos de los controles también se construye una imagen de desviación estándar del mismo grupo. Como última etapa la imagen junction es dividida por esta imagen de desviación estándar construida con la base de datos. Todo esto con el fin de normalizar los datos para poder comparar conjuntos de datos de distintos cerebros (Figura 7).

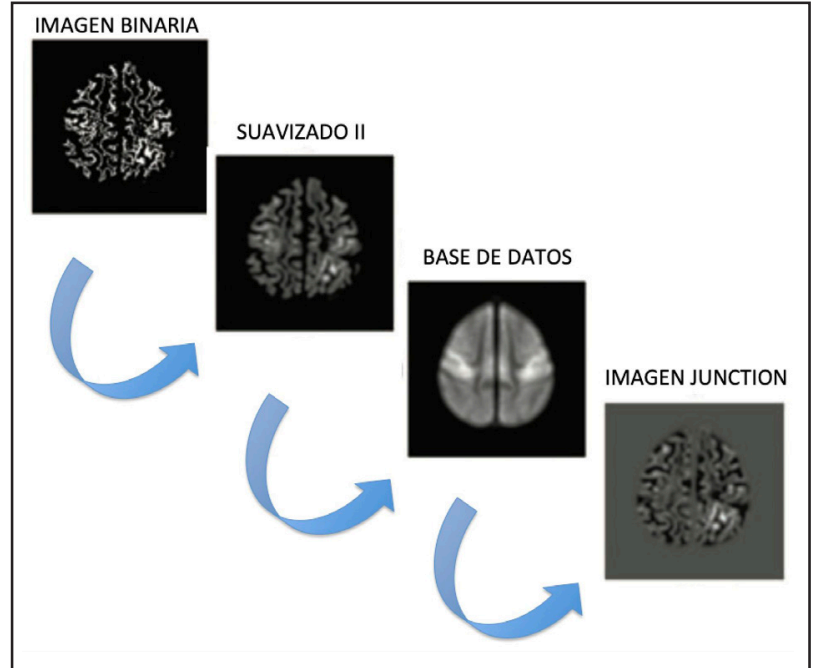

Figura 7: Proceso completo.

\section{Caso 1}

Se presenta un caso en donde se aplicó MAP en resonancias antiguas en imágenes de un paciente del año 2007 y 2011 en un resonador de 1.5T, en donde los resultados en la imagen fueron visualmente sutiles, pero donde MAP logró detectarlos como zonas sospechosas. La última resonancia magnética del paciente fue realizada en resonador de 3T año 2017, el hallazgo se hizo evidente en la imagen al igual que en el MAP (Figura 8).

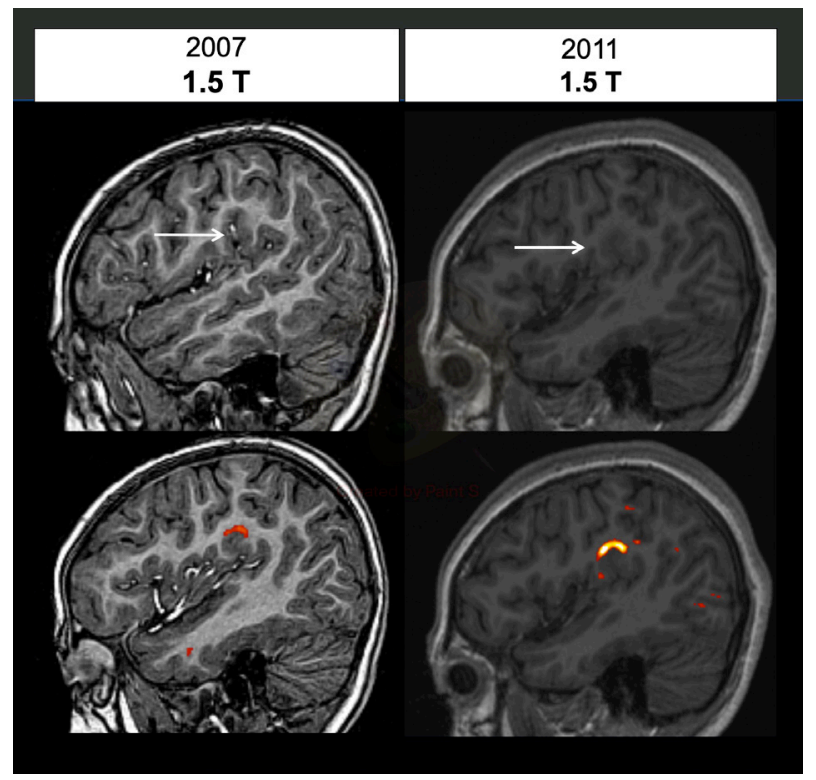

Figura 8: imágenes por resonancias del caso 1. 


\section{Caso 2}

Paciente de 3 años con diagnóstico de epilepsia. El electroencefalograma registra actividad irritativa interictal focal occipital izquierda. Se solicitó una RM de encéfalo con protocolo de epilepsia, que fue informada como normal. Se realizó MAP, con el siguiente resultado:

El estudio MAP junction muestra un área sospechosa en el giro témporo-occipital izquierdo, por lo tanto se estudia nuevamente y en esta oportunidad se analiza en forma dirigida el hallazgo revelado por MAP.

Finalmente se identifica un área de pérdida de la diferenciación córtico-subcortical asociada a alteración de la señal de la sustancia blanca subcortical en el giro témporo-occipital izquierdo, con el aspecto de una displasia cortical (Figuras 9a y 9b).

\section{Caso 3}

Paciente 5 años derivado a estudio con RM por epilepsia con sospecha de foco fronto-temporal derecho

El estudio morfológico y MAP permitieron diagnósticas dos áreas compatibles con displasias corticales en el giro frontal inferior derecho y en la circunvolución occípito-temporal lateral del mismo lado. Se reconoce pérdida de la diferenciación córtico-subcortical, asociadas a alteración de señal de la sustancia blanca subcortical que alcanza la pared de los ventrículos (Figuras 10a, 10b y 10c).

\section{Discusión y Conclusión}

Se ha dado a conocer el funcionamiento del programa MAP en sus distintas etapas y su aplicación a través de algunos casos desarrollados en nuestra institución.

Lograr entender el funcionamiento del programa paso a paso fue de suma importancia en el proceso de su utilización, ya que con estos conocimientos hemos podido optimizar su desempeño e identificar algunos errores y así poder encontrar la mejor solución para poder corregirlos, estamos actualmente en la recolección de datos de este último punto mencionado con el fin de continuar con nuestra línea de investigación con MAP.

Finalmente, la utilización de MAP en el análisis de las imágenes de resonancia magnética ha ayudado a nuestros neurorradióloga en la detección de displasias corticales focales.
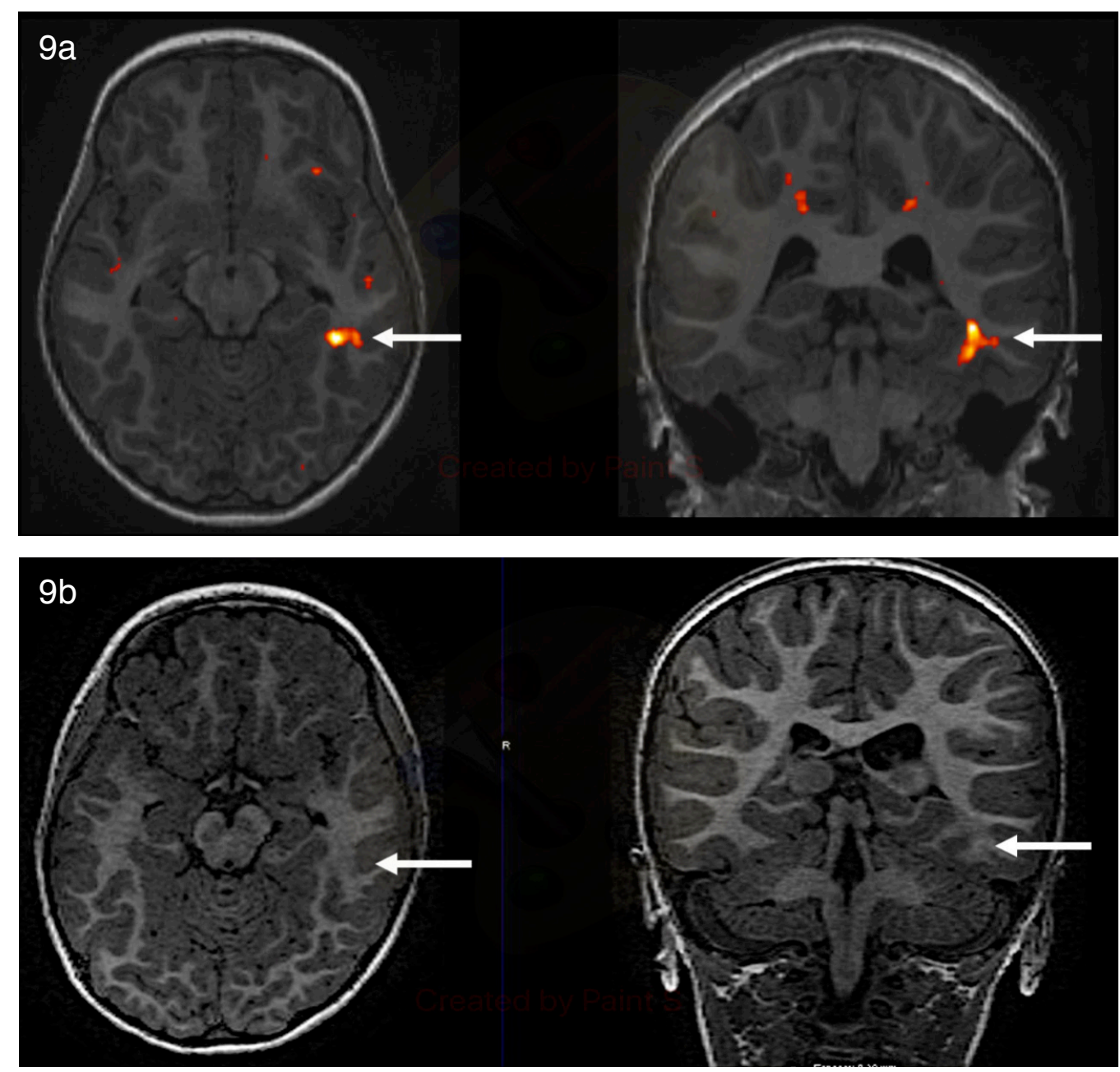

Figura 9 a, b: Imágenes por resonancias del caso 2. 

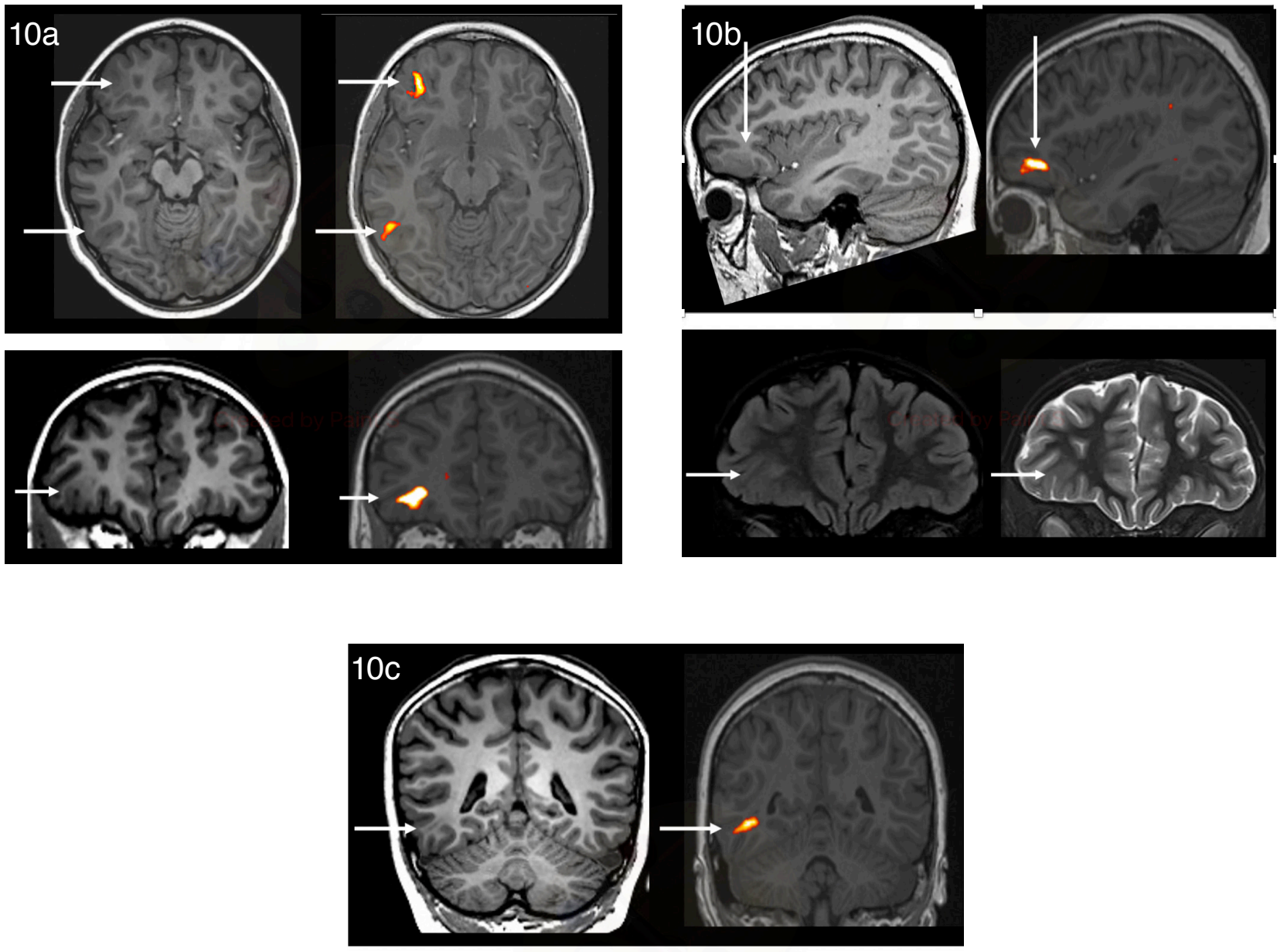

Figura 10 a, b, c: Imágenes por resonancias del caso 3.

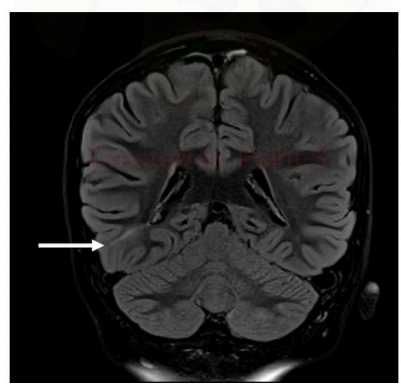

\section{Referencias}

1. Adler S, Lorio S, Jacques TS, Benova B, Gunny R, Cross JH, Carmichael DW. Towards in vivo focal cortical dysplasia phenotyping using quantitative MRI. Neurolmage: Clinical. 2017; 15: 95-105.

2. Semah F, Picot MC, Adam C, Broglin D, Arzimanoglou $A$, Bazin B, et al. Is the underlying cause of epilepsy a major prognostic factor for recurrence? Neurology 1998; 51: 1256-1262.

3. Santamarina E, Toledo M, Sueiras M, et al. Usefulness of intyravenous lacosamide in status epilepticus. J Neurol. 2013; 260: 3122-3128.

4. Tassi L, Pasquier B, Minotti L, Garbelli R, Kahane P,
Benabid AL, et al. Cortical dysplasia: electroclinical, imaging, and neuropatho logic study of 13 patients. Epilepsia 2001; 42: 112-123.

5. Huppertz HJ, Grimm C, Fauser S, Kassubek J, Mader I, Hochmuth A, Schulze-Bonhage A. Enhanced visualization of blurred gray-white matter junctions in focal cortical dysplasia by voxel-based 3D MRI analysis. Epilepsy research. 2005; 67(1-2): 35-50.

6. Doelken MT, Mennecke A, Huppertz HJ, Rampp S, Lukacs E, Kasper BS, Hammen T. Multimodality approach in cryptogenic epilepsy with focus on morphometric 3T MRI. Journal of Neuroradiology. 2012; 39(2): 87-96. 